\title{
Reflections on the Professional Values of Medical Students in Higher Vocational Colleges under the New Situation
}

\author{
Cao Xueguang ${ }^{1}$ \\ ${ }^{1}$ Honghe Health Vocational College, Mengzi, Yunnan 661199
}

Keywords: Higher vocational colleges; Medical students; Professional values

\begin{abstract}
This paper takes Honghe Health Vocational College as an example to investigate the medical beliefs, value orientation and learning attitude of medical students in the school, analyze the problems existing in it, expound the significance of setting up correct professional values for medical students in higher vocational colleges, and study how to adapt to the current situation changes, cultivate medical students' good professional attitudes and behaviors.
\end{abstract}

\section{Introduction}

At present, there is no clear definition of professional values. This paper combines the definitions of professional values by domestic and foreign scholars. The professional values are the specific performance of personal life choices, attitudes and goals in terms of occupation. It reflects people's occupation. Cognition, attitude and inclination are the direct expression and expression of job seekers' professional ideals. The International Medical Education Special Committee launched the "Basic Minimum Requirements for Global Medical Education" in early 2001. The article clearly states that "the scientific medical professional values include: the pursuit of excellence, altruism, responsibility, compassion, empathy, responsibility, honesty, integrity. And a rigorous scientific attitude of nine parts" [1]. Taking the Red River Health Vocational College as an example, the author conducts an in-depth investigation on the professional recognition, learning attitude and employment orientation of medical students in the school, comprehensively examines and evaluates their professional values, and proposes corresponding countermeasures and paths to further improve the medical students. Professional identity and professional attitude.

\section{Current status and existing problems of medical students' professional values in higher vocational colleges}

Medical students in higher vocational colleges are an important source of medical staff in the future, and their employment is directly oriented to the front line of medical care. Therefore, it is particularly important to understand the current situation of the professional values of medical students in higher vocational colleges in China and to analyze the existing problems.[2]

\subsection{Medical students in higher vocational colleges have low recognition of their majors}

There is a close relationship between students' professional recognition and their learning behavior. The professional recognition is high, the students' interest in professional learning is strong, and students are easy to get fun from the majors they have studied. After graduation, they have a high chance of choosing to work in related majors, which has a positive effect on promoting students' own employment. According to the survey of medical students in the school, some students choose medical majors because they are recognized and easy to work. Some students choose to study medicine under the encouragement or demand of their families. Most students choose medical majors to be blind or big. There are very few students who really like to study medicine. This has led to the high vocational medical students who do not have a clear understanding of the majors they have studied. After three years of high vocational education, they will study on courses of interest. The courses that are not interested will be ignored, and the professional foundation is not strong. There is good development in the professional field.[2] 
Compared with other occupations, medical talents grow relatively slowly, requiring long-term training and accumulation, low investment, low returns, high pressure and high risks. If medical students have low recognition of their profession, it will lead to insufficient learning motivation and the chance of engaging in related occupations will become smaller. The medical industry requires a high degree of specialization. Once a medical student quits and engages in professional-related work, the educational resources are wasted. In the case of low recognition of the professions that they have learned, even if medical students are engaged in medical work, their sense of responsibility and mission are not strong, and the concept and dedication of serving the people is difficult to establish.

\subsection{Utilitarian standards for employment orientation of medical students in higher vocational colleges}

"With the development of economic globalization, various cultural trends and values have a great impact on the ideals and beliefs of medical students. The trend of money worship and greed is prevalent. There are different degrees of ambiguity and value in medical students. Beliefs in confusion, lack of social responsibility, weak service awareness, lack of hard work and struggle, etc. [2]. While economic globalization and market economy bring us economic benefits, they also bring some bad influences. The prevalence of hedonism, money worship and individualism will have a negative impact on the attitude and orientation of medical students in school. [2]

In the case that China's market economic system is still not perfect, the competitiveness of the market economy and the interests driven by the original will easily dilute the professional belief of medical students, making the dedication of medical students become weak. The survey shows that medical students who are graduating will take the work environment, salary and welfare, social status, and enjoyment as the main factors in choosing a career. They pay more attention to whether the location of the employer is convenient, whether the work environment is comfortable, whether the material reward is considerable, and whether the self-demand can be met. When choosing to study opportunities or work places, cities with more developed economies become their ideal place. Sometimes I would rather be unemployed and try my best to avoid working in the grassroots health centers in towns and villages where the living environment is difficult. There is a shortage of talents in China's primary health care institutions. If there is no support from the health care industry in the past, people's health will be threatened and the happiness index will be greatly reduced.[3]

\subsection{The vocational values education of medical students in higher vocational colleges faces challenges}

Nowadays, most of the medical students in higher vocational schools are after 00 . They are individualized, curious, individualistic, and have insufficient social experience. They are not strong in judging good or bad, and sometimes cannot completely filter external bad information. Most of the medical students in higher vocational colleges have weak basic knowledge and low interest in learning. Coupled with some medical students who do not listen carefully during class, they do not pay attention to details in practice, which will affect the social practice and work of medical students. Therefore, how to stimulate the medical students' interest in learning, let them have the responsibility and passion for the medical work they are engaged in after graduation, which puts higher requirements on the vocational value education of higher vocational colleges.[3]

In addition, although China's medical service system has developed considerably, there is still a big gap compared with the health needs of the people. The public health system is not perfect, the allocation of medical and health resources is unreasonable, the medical treatment is expensive, the problem of medical treatment is difficult, and the situation of doctor-patient relationship is not harmonious. These are related to medical students and they are very concerned. Without proper guidance, medical students can easily interpret these news, thinking that medical work is not good, and social evaluation is not good, leading to their professional anxiety and confusion. 


\section{The Significance of Establishing Correct Professional Values for Medical Students in Higher Vocational Colleges}

The educator Tao Xingzhi said: "Morality is the foundation of being a man. It is fundamentally bad, even if you have some knowledge and skills, it is useless" [3]. Therefore, guiding students to form correct professional ethics and behaviors is not only the full realization of medical students' professional ideals, but also an inevitable trend to meet the needs of social development.

\subsection{Correct professional values help to improve the ideological and moral qualities of medical students}

This nature of medical rescue and ambulance determines that doctors must not only have superior medical skills, but also have noble moral character. Medical students are an important period of their growth, and a key stage in the formation of outlook on life, values, and worldview. At this stage, their quality has not yet been finalized, and they are easily influenced by non-mainstream values in society. If they are not properly guided, some bad ethos and illegitimate thoughts will easily invade their ideological and moral qualities.

The medical students' professional values education advocates the idea of "medical is benevolence and humanity-oriented", advocating the belief that "life is the most important, only the most respectable", and adheres to the principle of "guilty of profit, self-righteousness" and insists on "medical The spirit of "excellent, good deeds". These ideological concepts contained in the professional values can enable medical students to consciously establish the consciousness of serving the patients wholeheartedly and the belief that the patients' interests are above all else, stimulating the professional moral spirit of medical students to care for life and save the wounded and dying, and promote the conscious cultivation and improvement of medical students. Their own medical ethics.

\subsection{Correct professional values can guide medical students to choose their careers reasonably and adapt to social development}

Choosing a career is a process in which subjective will is united with objective reality. According to recent surveys, it is not difficult for medical students to find employment because medical students cannot find a job, but because their expectations are too high. Some medical students are affected by bad attitudes such as money worship. They believe that there is money and everything, and there is a lack of love for medical professions; some medical students are reluctant to go to work in remote areas. Correct professional values can help medical students to understand themselves objectively, rationalize the relationship between self-development, social needs, and family requirements, so that they have a clear self-positioning, establish a reasonable concept of career choice, get out of employment misunderstanding, and make their career development. Target positioning is in line with the needs of self-personality and social development, so that people can do their best when they do their best.[3]

Similarly, correct professional values can help medical students to constantly improve their knowledge structure, enhance their knowledge literacy and career ability, and gradually approach the individual career goals that are suitable for economic and social development, and ultimately achieve optimal development of their own. When the medical students' inner ideals contradict the work reality, the correct professional values will also play an auxiliary role, helping them to get out of the confused state as soon as possible, complete the role transformation, adapt to the new development requirements, integrate into the new environment, and better adapt.

\subsection{Correct professional values contribute to the harmonious development of China's medical and health undertakings}

In recent years, the relationship between doctors and patients has deteriorated, and medical disputes have occurred frequently. One of the reasons is that it is inseparable from the low level of professional ethics of some medical personnel. The service faced by medicine is the emotional and 
thoughtful person. The patient not only needs the medical staff to have excellent technology, but also pays attention to whether the medical staff has a harmonious working attitude, a high sense of responsibility and a noble moral sentiment. [3]If medical staff establishes the concept of serving the people, it can reduce the disputes caused by patients who are not satisfied with the quality of medical services, promote the sound development of doctor-patient relationship, and thus ensure the harmonious development of medical and health undertakings.

At present, the layout of our medical resources is unreasonable, and the development between urban and rural areas is not coordinated. Medical institutions are mainly distributed in cities, especially large and medium-sized cities, while small and medium-sized cities and townships have insufficient medical resources. The correct professional value helps to improve the professional ethics of medical students, improve the construction of medical and health talents, and help to meet the people's health and hygiene needs. In addition, through the guidance of professional values education, fostering the professionalism and dedication of medical students, encouraging them to work at the county level or below or underdeveloped primary medical institutions, can improve the medical and health conditions of the grassroots and ensure the primary health care. development of.

\section{How to Establish Correct Professional Values among Medical Students in Higher Vocational Colleges}

\subsection{Teaching content and methods should be targeted and carry out various forms of professional value education}

For medical students, the classroom is the main venue for their professional values education activities. Compared with undergraduate colleges, the learning atmosphere of higher vocational colleges is not strong, and students' learning efficiency is low. In order to stimulate the interest of medical students in higher vocational colleges, the teaching content and teaching methods must be in line with the actual situation of medical students, and must be targeted. For example, at the time of enrollment, the school can regard medical professional cognition as the main content of enrollment education, stimulate students' interest in learning through various forms, and cultivate the feelings of medical students on the majors they have studied. In the daily teaching, the content teaching should be combined with theory and practice, and the case should be used to explain the theory and enrich the theory, so that the content of the lecture is easy to understand. For the medical students who are graduating, an employment guidance course will be set up to help students to do psychological counseling and guide students to choose their careers reasonably.[3]

In terms of teaching methods, some medical majors can stimulate students' enthusiasm for learning through innovative curriculum. In the past, the ancients studied Chinese medicine, first went to the church with the master, and then delved into the basic theory. For students majoring in nursing, you can let them learn the skills first, then learn the basic theory or learn the skills and learn the theory course. In the teaching, the teaching requirements are implemented according to the work content of different medical technologies. For example, the medical nursing professional teaching can add the professional ethics of the nursing staff, and add the professional ethics of the pharmacy personnel and the medical ethics of the pharmacy personnel in the pharmacy and Chinese pharmacy profession. Targeted learning can not only enhance the learning effect, but also enable students to deeply understand the true meaning of professional values.[3]

\subsection{Giving play to the role of teachers and guiding students to establish correct professional values}

For medical students, teachers are the main force guiding students' medical practice. They are not only the focus of students' learning, but also the objects they learn and imitate. Teachers' personal strength, responsibility for work and pursuit of career in daily life work, the perception and understanding of life will have a subtle influence on students, and this influence is lasting and profound. Therefore, teachers must have a high level of business and good ideological quality, and they can play a role of exemplary and exemplary in guiding students' learning. 
In the course of preparing lessons, teachers can find some examples of the sages of the sages of the past dynasties. Similarly, the instructors can also collect advanced personal stories from the contemporary medical community, such as the annual "most beautiful doctors" figures or the surrounding life-seeking and dying incidents. These are the most vivid teaching materials for professional values education, through the promotion of their deeds. Explain, make students realize the personality charm and feelings possessed by these characters, and urge medical students to internalize morality into personal medical ethics, medical ethics, medical ethics, form a good professional ethics, and establish the concept of serving patients wholeheartedly. .

\subsection{Encourage medical students to actively participate in social practice and create opportunities for fostering professional values}

Social practice is one of the ways to improve the practical ability and professional comprehensive ability of medical students. The vocational values education in higher vocational colleges can not only stay at the theoretical instillation level. Schools should create more opportunities for medical students to contact patients and medical work practices, and encourage medical students to actively participate in social practice activities. For example, during school, the school can organize students to actively carry out voluntary medical examinations, summer trips to the countryside, voluntary medical treatment, and various medical students vocational skills competitions. During the graduation internship stage, the school can actively communicate with the internship hospital, and select some doctors with good morals and good skills to teach teachers, set an example in the transmission, help, and belt, and subtly shape the character and personality of medical students[3].

The professional ethics education and moral practice of medical students are complementary and mutually integrated. The school should guide students through the diversified social practice activities, use the medical expertise to provide medical services to the masses, deepen their understanding and understanding of medical work through social practice, and stimulate students' sense of responsibility and mission to learn the skills and save the wounded. Through social practice, students are guided to establish a good concept of medical ethics, cultivate medical students' good professional skills and professional ethics, and enable medical students to realize the organic unity of personal values and social values in medical and health practice.

\section{Conclusion}

The new situation and new development put forward new requirements for the medical students' professional values. The vocational value education of medical students in higher vocational colleges is a systematic project. It has long-term and arduous nature and needs to be managed by the whole society. Only in this way can we create a good environment for educating people and establish a scientific and complete system of professional ethics training in order to cultivate medical talents with rich theoretical knowledge, practical experience and good professionalism for the medical and health industry in China.

\section{References}

[1] International Medical Education Association. The minimum basic requirements for medical education in the world [M]. Foreign Medical Medical Education, 2002: 5.

[2] Xie Hongzhong. College Students' Values Orientation Based on the Analysis of Cultural Diversity Issues [M]. Beijing: Social Sciences Academic Press, 2010: 127.

[3] Tao Xingzhi. The Complete Volume of Tao Xingzhi's Complete Works [M]. Chengdu: Sichuan Education Press, 1991: 522-523. 